\title{
Vaccination and Autism: Evidence and Vaccine Compliance in Australia
}

\author{
Isaac Golden* \\ Research Member, National Institute of Integrative Medicine, Australia
}

Received: May 31, 2016; Accepted: July 06, 2016; Published: July 15, 2016

*Corresponding author: Isaac Golden PhD. Research Member, National Institute of Integrative Medicine, Australia, E-mail:admin@homstudy.net

\begin{abstract}
Introduction: Australian Government health sites state that there is no link between vaccination and autism. These claims influence public health policy surrounding vaccination in Australia.

Method: An examination of four Australian and one American Government sites was undertaken to identify original research articles examining the link between vaccination and autism. Claims concerning vaccination and autism are found to be based primarily on 23 original research articles. An analysis of relevant articles was made to see if a comparison between fully vaccinated (V) and completely unvaccinated (CUV) children was undertaken.

Results: It is shown that none of the articles identified undertook a substantive comparison between $V$ and CUV children. They do show that there is no significant difference in rates of autism in differently vaccinated groups of children, but without a comparison of $\mathrm{V}$ and CUV children they cannot make any final conclusions about a link between autism and vaccination.

Discussion: To assess whether appropriate research can be undertaken to further examine any possible association between vaccination and autism, the numbers of unvaccinated children in ageappropriate cohorts in Australia are estimated. Sufficient numbers are found to permit statistically significant findings to be made. Further, it is shown that using a retrospective cohort based analysis of children at primary school will remove ethical issues relating to the denial of vaccination.
\end{abstract}

Conclusion: It is concluded that the research identified will assist efforts to maximise vaccination compliance as well as better inform the Australia Government concerning public policy surrounding vaccination as well as the need for a vaccine damage compensation scheme.

Keywords: Autism; Vaccination; Hesitancy; Compliance; Unvaccinated

\section{Introduction}

Claims made concerning significant adverse events caused by vaccination have been vigorously contested by researchers. This particularly relates to the suggestion of a link between vaccination and autism, and a number of studies have been designed specifically to investigate this proposition.

For example, a 2014 review of ten studies examining whether there is a link between vaccination and autism concluded that there was no link [1]. However a further analysis demonstrated that because no comparisons were made between fully vaccinated (V) and completely unvaccinated (CUV) children, the review proved only that rates of autism were similar between differently vaccinated cohorts of children [2].

Attitudes of health authorities, politicians and the general public have been heavily influenced by research demonstrating no link between vaccination and autism. The purpose of this article is to evaluate the confidence that regulators and the public should have in conclusions arising from such studies, to determine whether further targeted research is needed and if so what type of research, and to assess some implications for public health policy and especially the potential impact of proposed new research on the level of vaccine compliance in Australia.

\section{Method}

An examination was made of all studies used to substantiate claims denying any link between vaccination and autism on the following four leading Australian (1-4) and one American government (5) sites:

1. The Department of Health [3].

2. The National Health and Medical Research Centre (NH\&MRC) [4].

3. The Australian Academy of Science (AAS) [5].

4. National Centre for Immunisation Research and Surveillance (NCIRS) [6].

5. Centre for Disease Control (CDC) $[7,8,9]$.

The Four Australian sites were chosen because they represent the most commonly referred to places where citizens can find official vaccine-related information. The American site was included because it was repeatedly referred to in the Australian Government publications listed.

Forty five original studies were identified as being referred to by these government agencies. The list was reduced by excluding 17 studies rejected by a 2012 Institute of Medicine (IOM) report because of either serious methodological limitations or because they provided data from a passive surveillance system lacking unvaccinated comparisons [10]. Five studies were reviews, 
leaving the following 23 original studies to be examined [1133]. Each of these 23 papers was examined to see if a meaningful comparison between $\mathrm{V}$ and CUV children was made.

In addition, an estimate is made of the numbers of unvaccinated children in Australia using available official data. This will allow a judgement to be made regarding the possibility of undertaking statistically significant research comparing vaccinated and completely unvaccinated children in terms of autism as well as other health measures in future research.

\section{Results}

Cross-referencing between the Government publications and the 23 studies is presented in Figure 1 to demonstrate the extent to which conclusions about vaccination and autism are based on this small number of original research studies which are repeatedly referenced. Whilst this analysis is focussed mainly on official Australian government publications it is likely to be similar in other countries. Common studies contained in the Taylor [1] analysis mentioned earlier are also shown. Fig. 1

None of the 23 original studies cited as disproving any link between vaccination and autism began with the expressed intention to compare the autism rates of $\mathrm{V}$ and CUV children, and no such comparisons were made. Only three studies $[20,28,30]$ identified CUV children, but there were so few that any meaningful comparison was impossible. The remaining studies that claimed to include "unvaccinated" children, actually analysed subjects who were vaccinated with other vaccines, but not with the targeted vaccine (usually MMR or vaccines containing thimerosal, the safety of which had been questioned). For example, Madsen was referred to in every Government publication, and based their conclusions on comparisons between children vaccinated with MMR and "the unvaccinated group" [11]. In fact children in "the unvaccinated group" had been vaccinated, but just not with MMR.

A classification of parents into seven types according to their approach to vaccination is shown in Table 1 . Differentiation between active and passive vaccine acceptors, as well as those hesitant to vaccinate have been well studied [36, 37]. Further groups are parents who don't know about vaccination, those who don't care, and others such as parents of children who cannot be vaccinated for medical reasons. The percentages of children in each group are estimates, as are the estimates of numbers of children in the 6-11 years cohort, which assumes an annual birth rate of 300,000 infants. It is also assumed that $1 / 4$ of the current vaccine refusers gave their children one or more vaccines before choosing to refuse further vaccines. Thus the figures in Table 1are estimates arising from assumptions based on vaccination status data and practical experience. They are therefore suggestive only, but they do provide a reasonable guide to the vaccination status of around 1.8 million children aged 6-11 years in Australia.

Eslick claimed that research comparing V and CUV children would be unethical if children were denied vaccines, and that selection bias and other confounders would make a meaningful

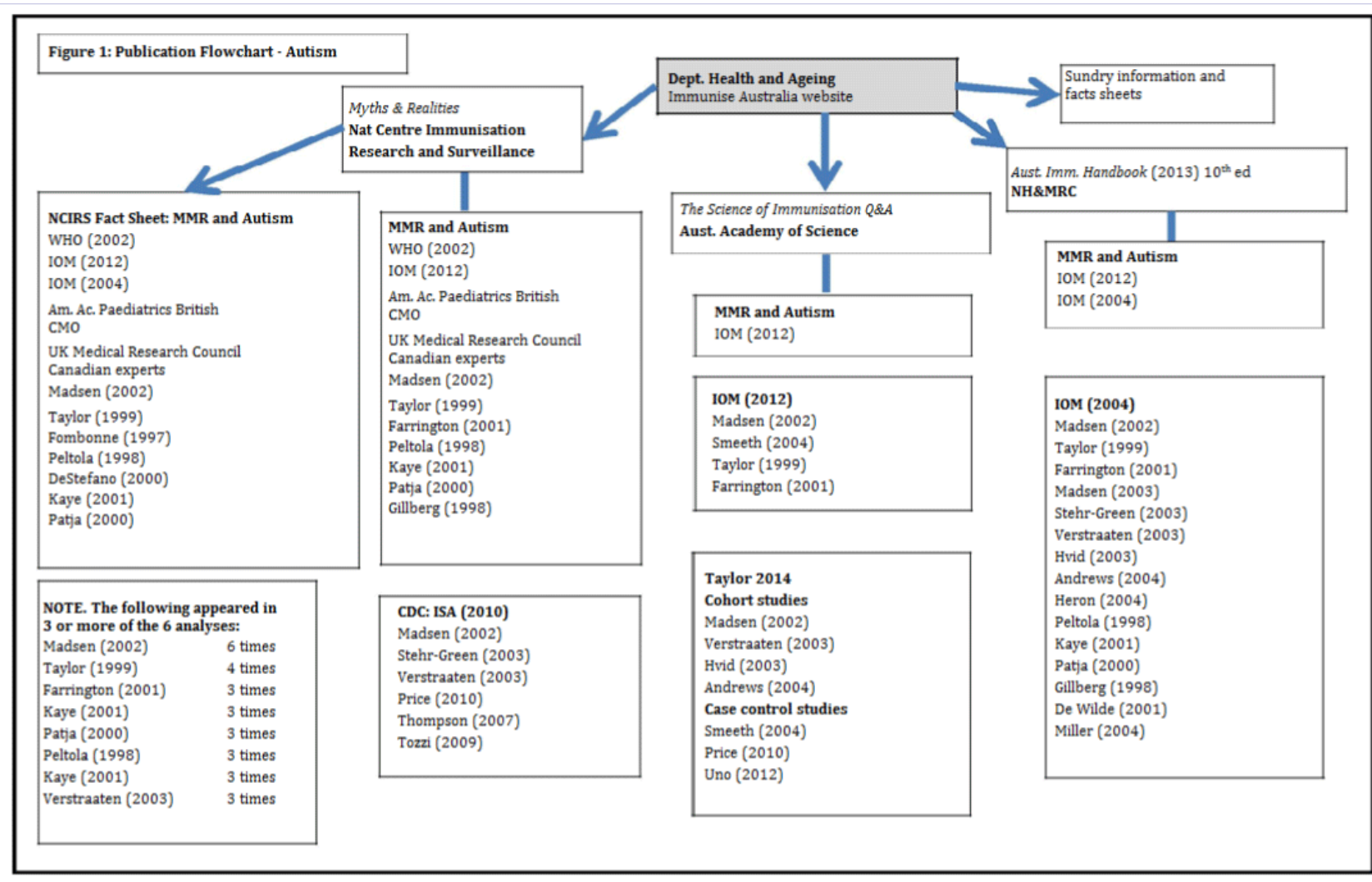

Figure 1: BMI in patients suffered with nonalcoholic fatty liver disease. 
Table 1: Vaccination compliance with classification of parents and estimated number of children aged 6-11 years by category

\begin{tabular}{|c|c|c|c|c|}
\hline$\%$ of & Vaccination & $\begin{array}{c}\text { Classification of } \\
\text { parents }\end{array}$ & $\%$ of & Estimated \\
\hline \multirow[t]{3}{*}{ children } & Status & & children & number of \\
\hline & & & & $\begin{array}{l}\text { children } \\
\text { aged }\end{array}$ \\
\hline & & & & 6-11 years \\
\hline \multirow[t]{9}{*}{$92 \%$} & Fully & $\begin{array}{l}\text { Active acceptors: } \\
\text { strongly }\end{array}$ & $30.0 \%$ & 540,000 \\
\hline & vaccinated & $\begin{array}{c}\text { believe in benefits } \\
\text { and seek }\end{array}$ & & \\
\hline & & to use vaccines & & \\
\hline & & $\begin{array}{l}\text { Passive } \\
\text { acceptors: } \\
\text { comply }\end{array}$ & $50.0 \%$ & 900,000 \\
\hline & & $\begin{array}{c}\text { with } \\
\text { recommendations }\end{array}$ & & \\
\hline & & $\begin{array}{l}\text { without strong } \\
\text { belief in }\end{array}$ & & \\
\hline & & benefits & & \\
\hline & & $\begin{array}{l}\text { Hesitators: } \\
\text { uncertain }\end{array}$ & $12.0 \%$ & 216,000 \\
\hline & & $\begin{array}{l}\text { whether to use, } \\
\text { delay or }\end{array}$ & & \\
\hline \multirow[t]{9}{*}{$8 \%$} & Partially & refuse vaccines & $3.5 \%$ & 63,000 \\
\hline & Vaccinated & & & \\
\hline & & $\begin{array}{c}\text { Refusers: make a } \\
\text { conscious }\end{array}$ & $0.5 \%$ & 9,000 \\
\hline & Completely & $\begin{array}{l}\text { decision not to } \\
\text { (continue to) }\end{array}$ & $1.5 \%$ & 27,000 \\
\hline & Unvaccinated & vaccinate & & \\
\hline & & $\begin{array}{l}\text { Hesitators: } \\
\text { Uncertain ... }\end{array}$ & $0.5 \%$ & 9,000 \\
\hline & & Don't know & $1.9 \%$ & 34,200 \\
\hline & & Don't care & & \\
\hline & & $\begin{array}{l}\text { Other, e.g. health } \\
\text { issues }\end{array}$ & $0.1 \%$ & 1,800 \\
\hline \multicolumn{4}{|c|}{$\begin{array}{l}\text { Estimated number of Australian children in 6-11 year } \\
\text { cohort }\end{array}$} & $1,800,000$ \\
\hline
\end{tabular}

comparison of V and CUV children impossible [38]. However use of a retrospective cohort study would eliminate ethical concerns as no children would be denied vaccines. Further, the numbers above show that appropriate matching of children within the same primary school would be possible given that there are significantly more $\mathrm{V}$ than CUV children in the primary school population, and this matching would deal with geographical, gender, economic and other biases.

\section{Discussion}

The government publications examined for this paper claim that that there is no link between vaccination and autism.
In Australia the consequences of these "no-link" claims are significant. Politicians make legislation based on this and similar advice, which is also used to inform the general public.

For example, in Australia (i) The Victorian State government introduced "No Jabs No Play" legislation from $1^{\text {st }}$ January 2016 which denies partially vaccinated and unvaccinated children access to childcare and preschool centres, and removes contentious and religious exemptions [39]; (ii) NSW State legislation allowing kindergarten managers to discriminate against unvaccinated children was copied in Queensland [40]; (iii) Unvaccinated children are denied Medicare support to receive the Australian Government's Healthy Kids Check which is designed "to improve the health and well-being of Australian children" [41]; (v) In 2015 the report titled A New System for Better Employment and Social Outcomes: Report of the Reference Group on Welfare Reform to the Minister for Social Services recommended that "The Child and Youth Payment should be conditional on the child or young person having up to date immunisations..." [42]; (vii) The 2015 Federal Budget papers stated that" From 1 January 2016, families will no longer be eligible for subsidized child care or the Family Tax Benefit Part A end-of-year supplement unless their child is up-to-date with all childhood immunisations", a policy supported by the Labour opposition and the Greens [43] This "no jab no pay" legislation has been introduced denying contentious and religious exemptions.

However some authors warn that attempts to marginalise parents with genuine concerns will prove counter-productive. For example, Macartney concluded that "Removing welfare payments or childcare rebates for parents who do not fully immunise their children is unnecessarily punitive and could have a number of negative repercussions" [44]. She referred to research showing that vaccination compliance will be improved by improving access and affordability of vaccines, and by developing trust between parents and vaccine providers [45].

The importance of having well conducted research comparing CUV and V children cannot be over stated. If the hesitant or refusing parents were provided with what they saw as conclusive proof that there is no link between vaccination and autism (as well as other chronic conditions) they may well reconsider their position. There is also a significant need to provide policy makers with complete evidence as they consider such things as the need for a vaccine damage compensation scheme - Australia is one of very few developed countries which do not have such a scheme [46].Conclusive research will also inform vaccine manufacturers about changes that may be needed to produce safer vaccines. Finally, definitive research will lessen the likelihood of court action for vaccine-induced-autism compensation which is emerging in other countries such as Italy and the USA [47].

Retrospective analyses of chronic health conditions in fully vaccinated and completely unvaccinated children based on information contained in existing national databases and clinical records, or from surveys of parents of children attending Australian primary schools, would enable needed studies to be undertaken without the ethical constraints involved in withholding vaccination. 
In Australia around 8\% of all children less than 5 years of age are not fully vaccinated [34]. It has been estimated that $1.7 \%$ of parents of children under 5 years choose not to vaccinate and instead lodge a conscientious objection form [35]. Some parents who object may not have lodged a form, and occasionally there are medical contraindications to vaccination. The $8 \%$ figure would include parents who began to vaccinate their children and then chose to stop, as well as parents who either forgot, don't know or don't care. The exact figure is unknown, but if we assume that around $4.0 \%$ of children are completely unvaccinated then this would equate to around 60,000 children in the cohort aged 6-11 years of age, i.e. children attending primary school. This provides a sufficient number of completely unvaccinated children to permit a statistically significant comparison with vaccinated children.

\section{Conclusions}

In order to conclusively prove that there is no link between autism and vaccination it is necessary to undertake substantive studies comparing fully vaccinated and completely unvaccinated children. To date there is no published evidence arising from such studies. Such retrospective research is possible among children attending primary school in Australia.

Until research comparing autism in fully vaccinated and completely unvaccinated children is undertaken and the results published in full, the demand by some vaccine refusers for what they regard as definitive evidence will remain unsatisfied, as will vaccine refusal and the potential for court action for vaccine damage compensation as seen in countries other than Australia.

\section{Acknowledgement}

The author acknowledges the helpful comments made by $\mathrm{Dr}$ C. Turville on earlier drafts of this article.

\section{References}

1. Taylor LE, Swerdfeger AL, Eslick GD. Vaccines are not associated with autism: an evidence-based meta- analysis of case-control and cohort studies. Vaccine. 2014;32(29):3623-3629.

2. Turville $\mathrm{C}$, Golden I. Autism and vaccination: The value of the evidence base of a recent meta-analysis. Vaccine. 2015;33(42):5494546. doi:10.1016/j.vaccine.2015.02.002.

3. Dept Health and Ageing. Measles-Mumps-Rubella immunisation, autism and inflammatory bowel disease: update. 1999;23(8).

4. NHMRC: Australian Technical Advisory Group on Immunisation. The Australian Immunisation Handbook. 10th ed. Canberra: Australian Government Department of Health. 2013.

5. The Science of Immunisation: Questions and Answers. Canberra. Australian Academy of Science 2012.

6. NCIRS 2009. Fact Sheet: MMR vaccine, inflammatory bowel disease and autism. 2013. Myths and Realities.

7. Centres for Disease Control 2010. Immunisation Safety and Autism Thimerosal and Autism Research Agenda.

8. Centres for Disease Control. Vaccines and Autism: A Summary of CDC Conducted or Sponsored Studies.

9. Centres for Disease Control. Vaccines Do Not Cause Autism.
10. IOM (Institute of Medicine). Adverse effects of vaccines: Evidence and causality. Washington, DC: The National Academies Press. 2012.

11. Madsen KM, A Hviid, M Vestergaard, D Schendel, J Wohlfahrt, P Thorsen, et al. A population-based study of measles, mumps, and rubella vaccination and autism. New England Journal of Medicine. 2002;347(19):1477-1482. DOI:10.1056/NEJMoa021134.

12. Smeeth L, Cook C, Fombonne E, Heavey L, Rodrigues LC, Smith PG, et al. MMR vaccination and pervasive developmental disorders: a case-control study. Lancet 2004;364:963-969. DOI:10.1016/ S01406736(04)17020-7

13. Taylor B, E Miller, CP Farrington, MC Petropoulos, I Favot-Mayaud, $\mathrm{J} \mathrm{Li}$, et al. Autism and measles, mumps, and rubella vaccine: No epidemiological evidence for a causal association. Lancet. 1999; 353(9169):2026-2029.

14. Farrington CP, E Miller, B Taylor. MMR and autism: Further evidence against a causal association. Vaccine. 2001;19(27):3632-3635.

15. Madsen KM, Lauritsen MB, Pedersen CB, Thorsen P, Plesner AM, Andersen $\mathrm{PH}$, et al. Thimerosal and the occurrence of autism: negative ecological evidence from Danish population-based data. Pediatrics. 2003; 112(3 Pt 1):604-606.

16. Stehr-Green P, Tull P, Stellfeld M, Mortenson PB, Simpson D. Autism and thimerosal-containing vaccines: lack of consistent evidence for an association. Am J Prev Med. 2003;25(2):101-106.

17. Verstraaten T, Davis RL, DeStefano F, Lieu TA, Rhodes PH, Black SB, et al. Safety of Thimerosal-Containing Vaccines: A Two-Phased Study of Computerised Health Maintenance Organization Databases. Pediatrics.2003; 112(5):1039-1048.

18. Hvid A, Stellfeld M, Wohlfahrt J, Melbye M. Association between thimerosal-containing vaccine and autism. JAMA. 2003; 290(13): 1763-1766. doi:10.1001/jama.290.13.1763.

19. Andrews N, Miller E, Grant A, Stowe J, Osborne V, Taylor B. Thimerosal exposure in infants and developmental disorders: a retrospective cohort study in the United Kingdom does not support a causal association. Pediatrics. 2004; 114(3):584-591. DOI: $10.1542 /$ peds.2003-1177-L.

20.Heron J, Golding J. 2004 Thimerosal exposure in infants and developmental disorders: a prospective cohort study in the United Kingdom does not support a causal association. Pediatrics. 2004;114(3):577-583.

21. Fombonne E, Du Mazaubrun C, Cans C, Grandjean H. Autism and associated medical disorders in a French epidemiological survey. J. Am. Academy of Child and Adolescent Psychiatry. 1997;36(11):15611569. DOI:10.1016/S0890-8567(09)66566-7.

22. Peltola HA, Patja P, Leinikki M, ValleI, Davidkin, M Paunio. No evidence for measles, mumps, and rubella vaccine-associated inflammatory bowel disease or autism in a 14-year prospective study. Lancet. 1998;351(9112):1327-1328. DOI:10.1016/S0140-6736(98)240189.

23. DeStefano F, Chen RT. Negative association between MMR and autism. Lancet. 1999; 353(9169):1987- 1988. DOI:10.1016/S01406736(99)00160-9.

24. Kaye JA, MD Melero-Montes, H Jick. Mumps, measles, and rubella vaccine and the incidence of autism recorded by general practitioners: A time trend analysis. British Medical Journal. 2001;322(7284):460463. Doi:10.1136/bmj.322.7284.460.

25. Patja A, I Davidkin, T Kurki, MJT Kallio, M Valle, H Peltola. Serious adverse events after measles-mumps-rubella vaccination during a 
fourteen-year prospective follow-up. Pediatric Infectious Disease Journal. 2000;19(12):1127-1134.

26. Gillberg C, Heijbel H. MMR and autism. Autism. 1998;2:423-424.

27. DeWilde S, Carey IM, Richards N, Hilton SR, Cook DG. Do children who become autistic consult more often after MMR vaccination? British J General Practice. 2001;51(464):226-227.

28. Miller E. Presentation to the Immunization Safety Review Committee Thimerosal and Developmental Problems Including Autism. Washington, DC. In Vaccines and Autism. Institute of Medicine. 2004.

29. Price CS, WW Thompson, B Goodson, ES Weintraub, LA Croen, VL Hinrichsen, et al. Prenatal and Infant Exposure to Thimerosal from vaccines and Immunoglobulins and Risk of Autism. Pediatrics. 2010 Doi:10.1542/peds.2010-0309.

30. Thompson WW, Price C, Goodson B, Shay DK, Benson P, Hinrichsen VL, et al. Early Thimerosal Exposure and Neuropsychological Outcomes at 7 to 10 Years. NEJM. 2007;357(13):1281-1292. DOI:10.1056/ NEJMoa071434.

31. Tozzi AE, Bisiacchi P, Tarantino V, DeMei B, D’Elia L, Chiarotti F, et al. 2009 Neuropsychological Performance 10 Years after Immunisation in Infancy with Thimerosal-Containing Vaccines. Pediatrics. 2009; 123(2):475-492. doi:10.1542/peds.2008-0795.

32. Hornig M, T Briese, T Buie, ML Bauman, G Lauwers, U Siemetzki, et al. Lack of association between measles virus vaccine and autism with enteropathy: A case-control study. PLoS ONE 2008;3(9):e3140. Doi:10.1371/journal.pone.0003140.

33. Uno Y, Uchiyama T, Kurowasa M, Aleksic B, Ozaki N. The combined measles, mumps, and rubella vaccines and the total number of vaccines are not associated with developmental autism spectrum disorder; The first case-control study in Asia. Vaccine. 2012;30:42924298. doi:10.1016/j.vaccine.2012.01.093.

34. National Centre for Immunisation. Research \& Surveillance. Childhood Immunisation Coverage estimates.

35. Sweet M. Australians must have their children fully immunised to receive benefit. BMJ. 2011;343:d7872. doi:10.1136/bmj.d7872.

36. Larson HJ, Jarrett C, Eckersberger E, Smith DMD, Paterson P. Understanding vaccine hesitancy around vaccines and vaccination from a global perspective: A systematic review of published literature, 2007-2012. Vaccine. 2014;32:2150-2159. DOI:10.1016/j. vaccine.2014.01.081

37. Yaqub O, Castle-Clarke S, Sevdalis N, Chataway J. Attitudes to vaccination: A critical review. Social Science \& Medicine. 2014;112:111. doi:10.1016/j.socscimed.2014.04.018

38. Hansen J. No jab, no play campaign launched to ban unvaccinated kids from childcare centres and preschools. The Sunday Telegraph. 2013.

39. Fraser K. Queensland Labor joins push to ban unvaccinated children from childcare centres. The Courier Mail. 2013.

40. Maher S. Rudd closes immunisation loophole. The Australian. 2013.

41. Department of Health and Ageing. 2013. The Healthy Kids Check Fact Sheet.

42. Department of Social Services. A New System for Better Employment and Social Outcomes: Report of the Reference Group on Welfare Reform to the Minister for Social Services. Commonwealth of Australia. $2015 ; 13$.

43. Australian Government, Budget Papers No.2, Expense Measures (cont). No Jab, No Pay. 